\title{
Accommodating change
}

\author{
Latifa Al-Abdulkarim ${ }^{1}$ - Katie Atkinson ${ }^{1}$. \\ Trevor Bench-Capon ${ }^{1}$
}

(C) The Author(s) 2016. This article is published with open access at Springerlink.com

\begin{abstract}
The third of Berman and Hafner's early nineties papers on reasoning with legal cases concerned temporal context, in particular the evolution of case law doctrine over time in response to new cases and against a changing background of social values and purposes. In this paper we consider the ways in which changes in case law doctrine can be accommodated in a recently proposed methodology for encapsulating case law theories (the ANGELIC methodology based on Abstract Dialectical Frameworks), and relate these changes the sources of change identified by Berman and Hafner.
\end{abstract}

Keywords Legal reasoning · Factors · ADF · Knowledge engineering · Argumentation · Values

\section{Introduction}

Although Carole Hafner worked on several topics over her long career, first on conceptual retrieval (Hafner 1987), and, later, on ontologies (Noy and Hafner 1997) and legal drafting (Hafner and Lauritsen 2007), many believe that the chief jewels in her crown were the series of three papers on reasoning with legal cases that she wrote with Don Berman for ICAIL between 1991 and 1995: Berman and Hafner (1991), Berman and Hafner (1993) and Berman and Hafner (1995), consolidated in

Latifa Al-Abdulkarim

latifak@liverpool.ac.uk

Katie Atkinson

katie@liverpool.ac.uk

Trevor Bench-Capon

tbc@liverpool.ac.uk

1 Department of Computer Science, University of Liverpool, Liverpool, England, UK 
Carole's paper for the issue of AI and Law in memory of Don (Hafner and Berman 2002). In the first half of the nineties, reasoning with legal cases was the main focus of AI and Law research in the US [in Europe, systems using rules based on formalisations of legislation, such as Sergot et al. (1986), were more in vogue at the time] and HYPO (Ashley 1991), CATO (Aleven 1997) and CABARET (Skalak and Rissland 1992) were the leading case based systems. In all three of these systems the cases in the case base were considered as being homogeneous and equal in status despite being drawn from different times (from 1945 onwards in CATO), jurisdictions (a variety of states in CATO as well as the Supreme Court) and levels of court, from circuit courts to the Supreme Court. While treating the cases as homogeneous is one valid way of doing research (philosophers often discuss arguments of their long dead predecessors as if they were contemporaries in the SCR), and allows the collection of a reasonable number of interesting cases, the three papers of Don and Carole explored how ignoring the distinctions of time, place and procedural context could distort the ways in which precedents were considered, and the roles played by them in new decisions.

The 1991 paper (Berman and Hafner 1991) examined the effect of taking procedural context seriously. This aspect has not been much explored since, although such information is sometimes included in legal ontologies such as Wyner and Hoekstra (2012), and the modelling of different levels of court in argument frameworks was explored in Wyner and Bench-Capon (2009).

The second paper (Berman and Hafner 1993), which introduced the notion of the purposes of the laws, or the social values they were designed to promote, as a way of guiding decisions in cases not yet covered by precedents, has proved highly influential, giving rise to a whole series of papers exploring the use of social values in legal case based reasoning. These include several papers from the issue of Artificial Intelligence and Law in memory of Don Berman (Bench-Capon 2002; Prakken 2002; Sartor 2002), later work such as Bench-Capon and Sartor (2003), and very recent work such as Prakken et al. (2015), Araszkiewicz et al. (2015) and AlAbdulkarim et al. (2015).

The third of the Berman and Hafner papers (1995) looked at how changes over time could affect case law, and in particular identified indicators that the case law was moving out of a period of stability (Levi 1961) and that precedents were likely to be refined or even overturned [called red flags in Berman and Hafner (1995)]. This was also the topic of Rissland and Friedman (1995), also from ICAIL 1995, and the later (Rissland and Xu 2011). In this paper we will focus not on detecting that change is coming but on accommodating change in an existing representation of case law. The representation we discuss will be that produced by the ANGELIC methodology (Al-Abdulkarim et al. 2016a), a recent proposal based on Abstract Dialectical Frameworks (ADF), a generalisation of Dung's argumentation frameworks (Dung 1995) introduced in Brewka and Woltran (2010) and refined in Brewka et al. (2013). That changes present problems for systems based on statute law had already been recognised in Bratley et al. (1991), and that systems needed to be designed with change in mind, was the motivation behind so-called isomorphic representations (Bench-Capon and Coenen 1991; Bench-Capon and Gordon 2009). 


\subsection{ADFs for case law}

For our exploration we will suppose that we have have a body of case law represented as an Abstract Dialectical Framework (ADF) (Brewka et al. 2013), as described in Al-Abdulkarim et al. (2016a), which offers a full description of how ADFs can be used to encapsulate a body of case law (the ANGELIC methodology). Formally an ADF can be defined (Brewka et al. 2013) as:

Definition 1 An ADF is a tuple $A D F=\langle S, L, C\rangle$ where $S$ is the set of statements (positions, nodes), $L$ is a subset of $S \times S$, a set of links: and $C=\left\{C_{s \in S}\right\}$ is a set of total functions $C_{s}: 2^{\operatorname{par}(s)} \rightarrow\{t, f\}$, one for each statement $s$. $C_{s}$ is called the acceptance condition of $s$.

The ANGELIC methodology partitions $L$ into links supporting the parent $(L+)$ and those attacking the parent $(L-)$. As an example of an ADF encapsulating case law we will use the Wild Animals cases introduced in Berman and Hafner (1993) and subsequently extended to include the famous Popov v Hayashi case (Wyner et al. 2007), and further refined in Bench-Capon (2012). The ADF is shown in tabular form in Table 1, and in diagrammatic form in Fig. 1.

The acceptance conditions for the nine non-leaf nodes are:

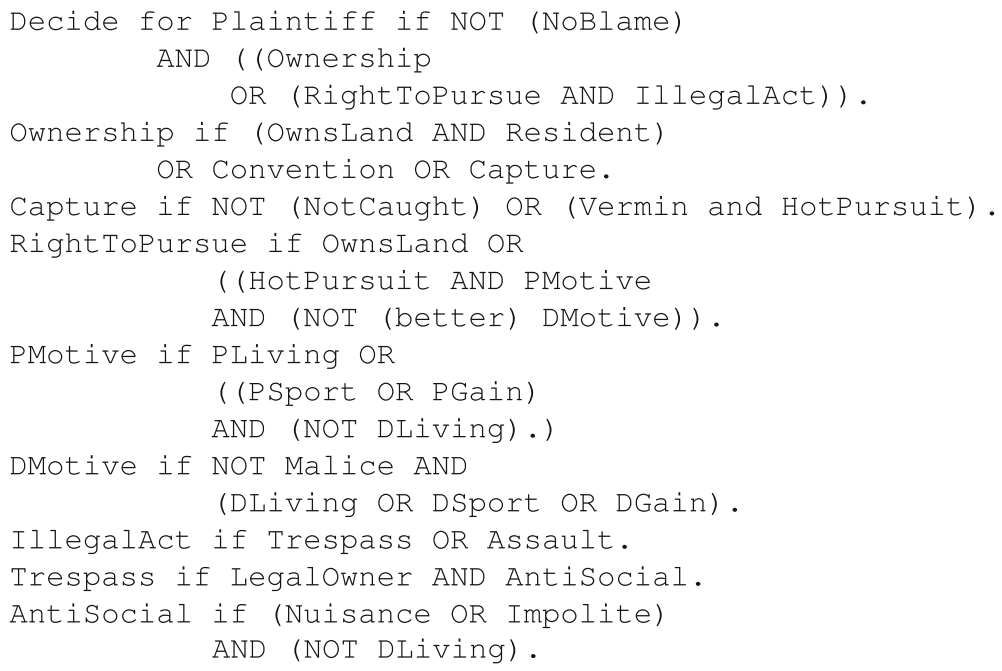

Informally ADFs have the advantages of combining a hierarchical structure of concepts, as found in the abstract factor hierarchy of CATO (Aleven 1997), with a traditional rule based representation of the acceptance conditions as found in work going back to Sergot et al. (1986). Moreover ADFs provide the rule base with a useful and sensible partitioning (Al-Abdulkarim et al. 2015), which makes for an effective modularisation of the design. The software engineering benefits of using ADFs as a design tool for constructing sytems based on case law are further discussed in Al-Abdulkarim et al. (2016a). 
Table 1 Wild animals as ADF

\begin{tabular}{lll}
\hline $\mathrm{S}$ & $\mathrm{L}+$ & $\mathrm{L}-$ \\
\hline $\begin{array}{l}\text { Decide for } \\
\text { Plaintiff }\end{array}$ & $\begin{array}{l}\text { Ownership, RightToPursue, } \\
\text { IllegalAct }\end{array}$ & NoBlame \\
Capture & HotPursuit, Vermin & NotCaught \\
Ownership & Convention, Capture, OwnsLand, & \\
& Res & DLiving \\
PMotive & Pliving, PSport, PGain & Malice \\
DMotive & DLiving, DSport, DGain & \\
OwnsLand & LegalOwner & DMotive \\
RightToPursue & OwnsLand, Pmotive, HotPursuit & DMotive \\
AntiSocial & Nuisance, Impolite & \\
Trespass & LegalOwner, AntiSocial & \\
IllegalAct & Assault, Trespass & \\
\hline
\end{tabular}

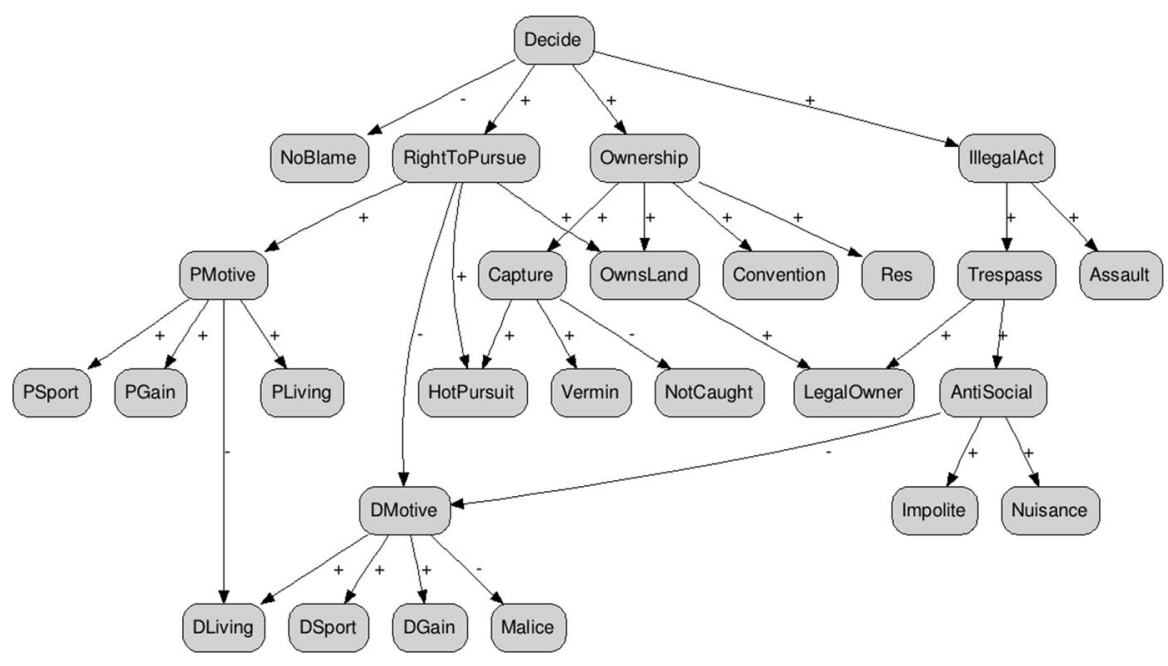

Fig. 1 ADF diagram for wild animals

As well as the Wild Animals domain, two other examples of ADFs encapsulating knowledge of case law are given in Al-Abdulkarim et al. (2016a), relating to US Trade Secrets as modelled in CATO (Aleven 1997) and IBP (Bruninghaus and Ashley 2003) and the automobile exception to the US Fourth Amendment, used in Rissland (1989) and Ashley et al. (2008). In this paper, however, since we are interested in structural modification of the ADF, we will use the purely abstract example shown in Fig. 2. Like the examples in Al-Abdulkarim et al. (2016a), and following the principles of Al-Abdulkarim et al. (2016c), there is an overall question tying the structure together, and layers for representation of issues, abstract factors and base level factors. 


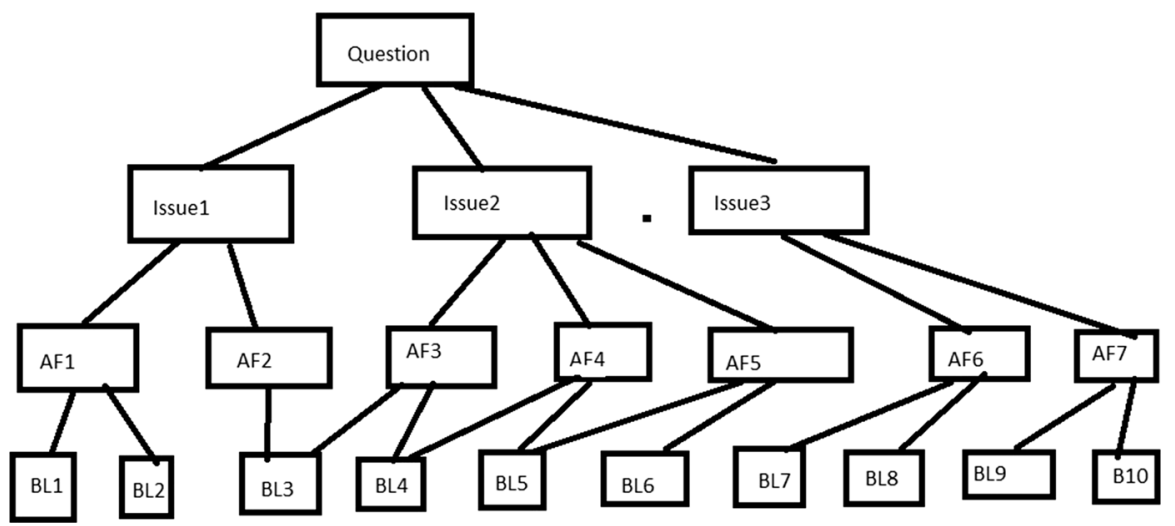

Fig. 2 Schematic case law ADF

\section{Types of changes}

In Rissland and Friedman (1995), which represents case knowledge as a binary decision tree, a number of different types of changes to the law are described in terms of changes to the structure used. A concept could be generalised (either by adding a disjunct or removing a conjunct) or restricted (either by removing a disjunct or adding a conjunct). The relevance of an attribute can change by moving up (or down) the tree. Finally the value of an attribute can be inverted by shifting it from the true branch to the false branch. Looking at changes in terms of modifications to the structure of the underlying tree is an excellent way of systematizing our investigation.

Returning to Berman and Hafner (1995), which represents cases in terms of dimensions, following HYPO (Ashley 1991), the solution proposed was to associate purposes [as introduced to legal CBR in Berman and Hafner (1993)] with the various dimensions. Note that this differs from the way values were used in much of the later work by other people which built on Berman and Hafner (1993), such as Bench-Capon and Sartor (2003) where values were associated with factors. Thus an important part of the background knowledge from which theories were constructed in Bench-Capon and Sartor (2003) was a set of factors, each associated with a value and the party the presence of the factor favoured. For individual cases, the facts determine a specific point on the dimensions, which in turn determines which party to the dispute is favoured on each dimension. This is very similar to the proposals in Prakken et al. (2015) and Al-Abdulkarim et al. (2016b) in which points on dimensions are used to bridge between facts and factors, and Bench-Capon et al. (2013), which uses facts represented as dimension points to link to values. Seeing changes as resulting from additional or changing purposes and value preferences was the key to the solution proposed in Berman and Hafner (1995).

The final addition to the representation of cases made in Berman and Hafner (1995) is that the outcome is not just the final result, but also a set of holdings. These intermediate conclusions can be seen as issues, or as abstract factors, and recognise 
that the change will affect particular aspects of the cases. This requires the ability to reason with portions of precedents in the manner of Branting (1991), and the holdings provide a way of dividing cases into sensible portions. As discussed in AlAbdulkarim et al. (2015), the ADF also localises the effect of precedents, and considers only a relevant subset of factors from precedents, so that there too the focus is on portions of precedents, rather than the whole cases. The holdings of Berman and Hafner (1995) can be seen as corresponding to the abstract factor and issue nodes of the ADF, and supplying their acceptance conditions.

Thus we find that Berman and Hafner (1995) identify several additional components which should be included in the case representations to enable the modelling of changes in case law. The additions were ahead of their time: it took more than five years before the importance of intermediate concepts was properly recognised (Ashley and Brüninghaus 2003; Atkinson and Bench-Capon 2005; Lindahl and Odelstad 2006), and even longer for the role of dimensions in bridging from facts to factors (Prakken et al. 2015; Bench-Capon and Bex 2015; AlAbdulkarim et al. 2016b, c) to be seen as essential.

\section{Amending an ADF}

In Al-Abdulkarim et al. (2016a) modification of the ADF was discussed in the context of refining a program to provide better performance against a set of test data. These modifications involved either altering the priorities in the acceptance tests, or adding a node (supporting or attacking). In that paper we did not consider the removal of nodes, on the basis that the same effect can be achieved by lowering the relative priorities, but for changes in the law, whether statute law or case law doctrine, removal is an additional possibility. A key difference between the ADF of Al-Abdulkarim et al. (2016a) and the decision tree of Rissland and Friedman (1995) is that the children of a node in an ADF do not distinguish conjunctions and disjunctions, and there are no true branches and false branches: these aspects are determined, for each node individually, in the acceptance conditions associated with the node (although the partitioning of $L$ does indicate the effect of a node on its parents).

We will express the acceptance conditions as in Al-Abdulkarim et al. (2016a) and as given for the Wild Animals cases in Sect. 1.1: that is, as a series of tests, to be applied in turn (until one succeeds), and a default. There are essentially three patterns. Consider Issue1 and its children AF1 and AF2. These may form a conjunction:

\section{AC1}

Accept Issue1 if AF1 and AF2.

Reject Issue1.

Alternatively they may represent independent tests, effectively a disjunction, giving rise (as in logic programs) to two clauses and the default: 


\section{$\mathrm{AC2}$}

Accept Issue1 if AF1.

Accept Issue1 if AF2.

Reject Issue1.

Finally the two abstract factors may have different effects on the acceptability of their parent, giving rise to an exception or rebuttal structure:

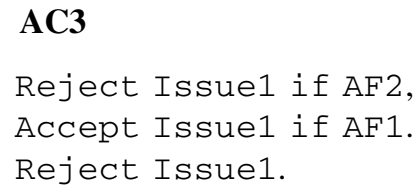

In AC3, AF2 is the exception. Only when AF2 does not hold, does AF1 suffice to make Issue1 acceptable. Note that the defaults may either suggest acceptance or rejection. The order of the tests represents the relative priority of the two abstract factors. Thus for example Issue 2 might have acceptance conditions:

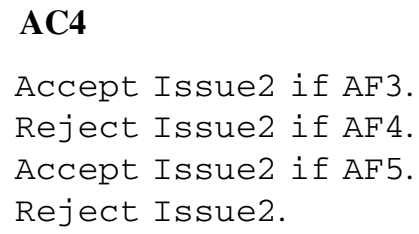

which would represent a preference for AF3 over AF4, and for AF4 over AF5. In the previous section we saw that there were essentially four types of change:

- Broadening: called genralisation in Rissland and Friedman (1995) in which a concept is modified to apply to more cases;

- Narrowing: called restriction in Rissland and Friedman (1995) in which a concept is modified to apply to fewer cases;

- Priority: called relevance in Rissland and Friedman (1995), in which an existing preference relation is changed; and

- Effect: called inversion in Rissland and Friedman (1995), in which a concept changes the party it favours.

In the following subsections we will look at each of these in turn.

\subsection{Broadening}

Whereas Rissland and Friedman (1995) envisaged changes being reflected in the structure of their decision tree, theory change in an ADF will not always result in a change in the visible structure, since sometimes the effect can be achieved by modifications to the acceptance conditions. For example, consider AC1. We can broaden Issue 1 by amending the conjunction to a disjunction, which would modify it to give AC2. Such an example is provided by the automobile exception to the US 
Fourth Amendment. In California $v$ Carney $^{1}$ all are agreed that the automobile exception arises from the greater urgency arising from the mobility of cars, and from the reduced expectations associated with vehicles, since they are subject to routine inspection. There is, however, some discussion about whether these factors can be considered independently $(\mathrm{AC} 2$ ) or whether both are needed for the exception to apply (AC1).

Sometimes, however, a change in the structure is required. There is no discussion of privacy in the original automobile exception case (Carroll $v$ United States ${ }^{2}$ ), although the reduced expectations of privacy associated with automobiles is an established feature of such cases by the time of South Dakota v Opperman. ${ }^{3}$ Thus at sometime between 1925 and 1976, the reduced expectations of privacy must have been introduced. Whether this broadened or narrowed the concept depends on whether $\mathrm{AC} 1$ or $\mathrm{AC} 2$ is the appropriate representation of the new acceptance conditions: for broadening, the new factor will give rise to an extra disjunctive test (AC2). The important difference is that the new node will introduce a new value (in this case privacy) into consideration of the issue, reflecting the key role given to purposes in Berman and Hafner (1995).

If the new node is at the Issue level, it will require elaboration in terms of abstract and base level factors, Thus when Issue1 was introduced to the ADF of Fig. 1, it would bring with it AF1, AF2, BL1, BL2 and BL3 (unless BL3 was already present because of its role in determining AF3). Similarly, if the new node is an abstract factor, it may require new base level factors to decide its acceptance. Finally the new node may be a base-level factor, which will not require anything additional in the ADF, although, if it cannot be seen as a point of an existing dimension, it will require a new dimension, if we are using dimensions. Typically a new value will give rise to a new dimension, which may further lead to the identification of additional base level factors, for use in later cases. It is, however, possible, that (as with BL3 above) no new nodes are needed since the node already exists in another part of the ADF. In such a case we need a new link, but no new node. Note that to broaden the concept the node must appear as a disjunctive test in the acceptance condition of the new abstract factor.

Broadening can also be effected by removal of a node. For example if an exception is removed, the concept will apply to more cases. For instance, removing AF4 from AC4 above will broaden Issue 2. Also broadening is effected if the node removed was used conjunctively in the acceptance conditions of the parent. For example in AC1, if AF2 is removed, this will broaden Issue1 so that it applies to all cases with AF1, rather than just the subset for which AF2 also holds.

\subsection{Narrowing}

Narrowing is similar to broadening but relies on the introduction of conjunctions rather than disjunctions. Thus changing from AC2 to AC1 will narrow Issue1.

\footnotetext{
1471 U.S. 386 (1985).

267 U.S. 132 (1925).

3428 U.S. 364 (1976).
} 
Similarly a new node will narrow a concept if it appears in the truth conditions either as an additional conjunct on one or more tests, or as an exception in the manner of AF2 in AC3.

Narrowing can also be effected by removing a node which was appearing in a disjunctive test (e.g. AF1 or AF2 in AC2). This, however, is quite a drastic change: first removing a node (if it is higher than the base level factors) will prune off a whole subtree, so that a number of factors which were previously considered relevant will cease to be so. This may also result in the disappearance of one or more dimensions, which will radically change the case law of the domain. Moreover, the removal of a node may result in the removal of a value, which might need some kind of societal shift to provide a justification.

There are examples of a value being rejected. For instance, consider the opinion of Brennan J. in Furman v Georgia, ${ }^{4}$ a US Supreme Court case involving a decision as to whether capital punishment should be considered "cruel and unusual" under the Eighth Amendment. The case is discussed in Bench-Capon (2009). Among the questions raised was whether retribution should still be considered a legitimate purpose of punishment in the US of the seventies. Although it was not agreed that retribution had ceased to be a worthy value, Brennan holding that any retributive needs could be satisfied by a fate short of death, the Court could have held that this was so, requiring that nodes justified by this value be removed from the ADF. The problem is that such a move would represent a clear departure from stare decisis. In the UK, the House of Lords had been bound to follow its own previous decisions since London Street Tramways v London County Council [1898] AC 375. This obligation was, however, removed in a Practice Statement of 1966, which enabled the House of Lords to adapt English law to meet changing social conditions. This power was exercised in $R v G$ and $R,{ }^{5}$ in which the House of Lords overruled its decision in Caldwell. ${ }^{6}$ These cases concerned "recklessness". This power is rarely exercised: there were fewer than twenty such instances in the first forty years of its operation (some eighty or ninety were heard in each of these years).

The US Supreme Court is able to overrule itself, but is also reluctant to do so. With respect to the automobile exception, the case of California $v$ Acevedo ${ }^{7}$ seemed to overrule both $U S v$ Chadwick $^{8}$ and Arkansas $v$ Sanders ${ }^{9}$ by holding that a warrantless search of an automobile was permissible, even when the probable cause only extended to a container or item of luggage within the vehicle; Blackmun $\mathbf{J}$ states:

Although we have recognized firmly that the doctrine of stare decisis serves profoundly important purposes in our legal system, this Court has overruled a

\footnotetext{
4408 U.S. 238 (1972).

5 R v G and R [2003], AC 1034.

${ }^{6} \mathrm{R}$ v Caldwell [1982] AC 341.

7500 U.S. 565 (1991).

8433 U.S. 1 (1977).

9442 U.S. 753 (1979).
} 
prior case on the comparatively rare occasion when it has bred confusion or been a derelict or led to anomalous results.

Thus removal of a node is possible, but not to be undertaken lightly. Indeed, Blackmun claims that Avecedo did not in fact overrule the previous cases. This, however, was disputed in the dissent by Stevens J with Marshall J concurring:

Relying on arguments that conservative judges have repeatedly rejected in past cases, the Court today-despite its disclaimer to the contrary-enlarges the scope of the automobile exception

The discussion in this section indicates that removal of a node is possible, but is something of a last resort. Very often a similar effect can be achieved by reordering the tests in the acceptance conditions. Thus in AC3, the absence of AF2 is a necessary, but insufficient condition for the acceptance of Issue1. If it were placed below AF1, its presence would become a sufficient (but unnecessary) condition. In fact, following the modification, it would have no effect, since the default would lead to rejection of Issue 1 anyway if it were absent. Retaining it, however, allows for the possibility of an additional node for acceptance being introduced at a later date, which if placed below AF2 would revive its usefulness in some cases. This leads us to consider priorities.

\subsection{Priority}

The ordering of the tests in the acceptance conditions is determined by the relevant priorities given to the children nodes. These can be explained in terms of value preferences (Al-Abdulkarim et al. 2015). Note that the priorities are organised on a node-by-node basis, and there is no requirement for consistency of preferences across nodes. This constraint could be imposed, but we currently feel that the flexibility has more benefits than costs.

Thus a change in priorities is effected by reordering the tests. AC4 reflects the ordering $A F 5 \prec A F 4 \prec A F 3$, so if AF4 became preferred to AF3, this could be effected by exchanging the position of the corresponding tests.

Changes in priority are likely to be quite common. Firstly it is very likely that not all the priorities represented in the ADF will have a justification in the precedent cases, but will have been determined by the judgement of the knowledge engineer. Whilst, as more cases are decided, many of the judgements will be confirmed, some new cases may require tuning of the acceptance conditions for particular nodes. Moreover, and more importantly, it needs to be recognised that the value preferences of society change over time. Sometimes this will be a case of evolution, as with retribution discussed above for capital punishment, but sometimes it will be more like a pendulum. This is well described in Christie (2012), particularly in the context of values expressed as legal principles. These often come in opposing pairs: for example it is desirable to draw a bright line in the interests of legal certainty, but it also necessary to deal out justice in the light of the nuances of the facts of individual cases. Similarly the amount of discretion it is held proper for judges to exercise will vary. As the pendulum swings, so the preference expressed in the 
associated case law may change. For example, although it was held in Pierson $v$ Post, as discussed in Berman and Hafner (1993) that the need for clarity outweighed any social benefit that would arise from encouraging fox hunting, the balance may have been struck differently at another time or in another place.

\subsection{Effect}

The last category of change in Rissland and Friedman (1995) concerns the effect of a factor. In CATO factors are supposed to always favour one party or the other, and this is an inherent feature of the factor. This is a key part of factor based reasoning, and an essential component of both Bench-Capon and Sartor (2003) and Horty and Bench-Capon (2012). Thus in the discussion of Pierson v Post in Berman and Hafner (1993) we have a factor NotCaught which definitely favours the defendant. Much of the argument, however, concerns what should count as caught and, as discussed in Bench-Capon and Rissland (2001), the whole case may turn on this point. In Pierson, it is argued, following the authority of Justinian, that actual bodily possession was required. It was, however, also argued, following other authorities, that mortal wounding, or even certain capture, would suffice. The counsel for Post argued that even being in hot pursuit should count [see the discussion in BenchCapon and Rissland (2001)]. Here we might see NotCaught as an abstract factor and BodilyPossession, MortalWounding, CertainCapture and HotPursuit as base level factors. The presence of any of the last three of these would lead to the acceptance of NotCaught and so all three would be regarded as pro-defendant factors. Only BodilyPossession is pro-plaintiff.

\section{AC5}

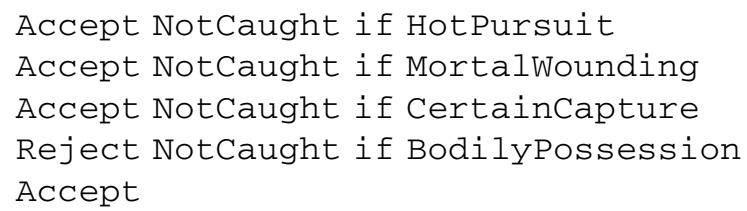

Now if later it was decided that Justinian was too restrictive, then one of the other factors would change from accept to reject. This is more than a re-ordering of priorities: it involves a change in the party favoured by the factor, to reflect some social change. As the pendulum discussed above in connection with priorities swings, it will move along the dimension and modify the cross-over point, turning pro-plaintiff base level factors into pro-defendant factors as it moves one way, and back again when it returns. Essentially we are modifying what we are prepared to accept as promoting the value underlying the dimension.

\subsection{Importance of values}

What the above shows is how right Berman and Hafner (1995) were to link changes in case law to dimensions and changes in recognised social values and their priorities. Although some modifications, especially in the early stages of case law 
development, will draw on values already present, many of the modifications, of all four types, will result from values becoming accepted or rejected, the preferences between them being modified, or changes in what counts as promotion. This is how the law can reflect social change, while retaining the same legislation.

\section{Berman and Hafner's red flags}

In the previous section we have considered how changes over time can be incorporated in the representation of a body of case law as an ADF. Our perspective thus far has been very much post hoc. However, Berman and Hafner (1995) were especially concerned with anticipating the need for change. In particular they wanted to know how confident they should be in a prediction based on a representation of existing case law. To this end they identified five "red flags" which were supposed to warn the user of a putative system to be cautious about relying on the predictions, since the law might be about to change, and the current case might be the one where that change was to become manifest.

The first of these red flags was where the precedent had been explicitly overruled. It is quite possible that the decision not to modify the representation immediately had been taken by the user, since a single decision might be a rogue decision, and we might find it ignored in subsequent decisions. The existence of such a decision should, however, require that the system be used with caution until it became clear whether the change was genuine or a mistake. What should be done, during the period when change is under consideration, is to annotate the program so that the user is made aware that the prediction offered relies on a decision which has been overruled.

An explicit overruling is easy enough to spot, provided someone is monitoring the decisions, but the second red flag relates to implicit overruling, and so needs more than a superficial look at the decision. If, however, we have a working system to maintain, the system itself can be used to detect such decisions. If we run the case through the system and a divergent answer is given, we may suspect an implicit overruling. The node which gave rise to the divergence can be readily spotted as described in Al-Abdulkarim et al. (2016a). We can then annotate the program, as for an explicit overturning, to sound a note of caution to users until it becomes clear whether we should adopt the change.

The third red flag is where the ratio decidendi is overruled, although the facts differ significantly. In Berman and Hafner (1995) the example was where an issue is applicable to two distinct domains, but was resolved differently in the two domains. ${ }^{10}$ Clearly this difference in value preferences should ring a warning bell, but it will be hard to detect: we may not be monitoring cases in this other domain, let alone have an operative system which will detect the divergence. A problem with representing law is that to build a software system we need to scope the domain:

\footnotetext{
${ }^{10}$ The issue in Berman and Hafner (1995) is whether a case should be tried in the jurisdiction where the event took place, or in the jurisdiction which was the "centre of gravity". Thus if two New Yorkers have a motor accident in New Hampshire, where should the case be heard? Similar cases could arise in other domains: for example if two New Yorkers struck an agreement when they happened to be in New Jersey.
} 
indeed scoping the system and deciding what will be in the system and what will not is an essential early step in Software Engineering methodologies (e.g. Connolly and Begg 2004). But the law is, in the phrase associated with Ronald Dworkin, a "seamless web", and such scoping may be difficult or even impossible. If detected, this red flag can be handled in the same way of the previous two, but detection cannot be assured.

The fourth red flag is when a "shift in the relative priority of competing purposes is in evidence from the court's tendency to make a rule increasingly narrow by "distinguishing away situations where one might have expected the rule to apply" (Berman and Hafner 1995, p. 45). We saw in Sect. 3.2 how a concept could be narrowed, by adding conjuncts to truth conditions, and by adding exception structures. In order to pick up on this flag a person must notice a pattern in the series of changes, namely that the role of nodes related to a particular value is being restricted by nodes relating to some other value, or values. Such a pattern is likely to indicate a loss of favour of the value being restricted. An alternative pattern might arise from nodes relating to a particular value being used to restrict nodes relating to other values, suggesting that the preference for the value is increasing. Such patterns will, however, emerge only from a reasonably large number of modifications arising in the domain of interest. Probably the clearest sign is when we get a new exception structure, of the form of AC3. AC3 shows a clear preference for the value associated with AF2 over that associated with AF1, and may give us warning that a shift in value preferences has occurred. This in turn should lead us to reconsider other expressions of preference and where the new preference is not respected annotate it with an appropriate warning.

The final red flag is where "a general shift in the relative priority of competing purposes is in evidence from cases across legal domains" (Berman and Hafner 1995, p. 46). Like the third red flag this requires the monitoring of domains other than the one represented. And like the fourth red flag it is somewhat nebulous. The chances of detection are thus lower than the other red flags. Perhaps, however, to talk about competing purposes in evidence from legal decisions is to place too narrow bounds on where such shifts in values can be discovered. Value preferences are manifested in social attitudes as well as law and while sometimes the law is ahead of the public in terms of social change (capital punishment is a UK example), in others it lags behind. An example of the latter can be perhaps been seen in the area of rights over a matrimonial home as seen in Pettitt $v$ Pettitt. ${ }^{11}$ We consider that identifying instances of this fifth red flag might prove difficult and unreliable.

In Berman and Hafner (1995) an algorithm is provided for using these red flags to provide a numeric measure to which a precedent had been weakened by subsequent red flags. This, however, does not discuss how red flags can be identified and so has not really been used in any empirical investigation, and so we will not discuss it further.

\footnotetext{
11 Pettitt v Pettitt [1970] AC 777. Pettitt is an English case in which the wife had used her own money to buy a house during the marriage, meaning the title to the house was in the wife's name, and both she and her husband lived there until the wife left the husband. The husband claimed that he had carried out a considerable number of improvements to the house and garden and sought a beneficial interest in the proceeds of sale of the property.
} 


\section{Related work}

In this section we will discuss some related work.

\subsection{Detecting change}

The investigation in Rissland and $\mathrm{Xu}$ (2011) concerned the response to surprising decisions which apparently went against existing case law: so-called Black Swans: "novel, surprising, provocative, exceptional cases". In order for Black Swans to represent a change rather than a single aberration they need to be followed by Gray Cygnets, cases which reinforce the decision and accelerate legal change. The domain investigated was recovery of damages by a remote buyer, a sequence of cases initiated by the decision in Thomas and Wife v. Winchester. ${ }^{12}$ Like Berman and Hafner's red flags, this work relates to when we need to change our ADF, rather than any particular changes we might need to make.

\subsection{Responding to change}

Although there has been work on detecting, anticipating and responding to change, little attention has been paid to the evolution of case law. Exceptions are Henderson and Bench-Capon (2001) and Priddle-Higson (2010), but neither of these seem to have attracted any follow up attention. Perhaps this is a topic worthy of future AI and Law investigation. The maintenance of knowledge based systems, always something of a Cinderella subject, seems to have attracted little attention since the 1990s, and so Coenen and Bench-Capon (1993) remains a useful reference.

\subsection{Theory construction}

In both Al-Abdulkarim et al. (2016a) and Bench-Capon and Sartor (2003) the intention is to encapsulate a theory derived from a body of case law. But whereas Al-Abdulkarim et al. (2016a) consider all the precedents to be included at the outset, and aim to capture them all in the ADF, in Bench-Capon and Sartor (2003) the theories include cases one by one and build upon them by adding more cases from the available precedents to refine the theory until the domain is explained as far as it can be. Therefore Bench-Capon and Sartor (2003) also come with a set of operators for extending the theory, as new cases are included. Although these are not new cases, but cases chosen from the case background, there are clear similarities with the changes to a theory expressed as an ADF as described in Sect. 3 .

A theory in Bench-Capon and Sartor (2003) is a five-tuple comprising a set of cases, a set of factors, a set of rules, a set of preferences between these rules, and a set of value preferences intended to justify the rules. As an example we will consider the theory intended to explain Pierson $v$ Post, ${ }^{13}$ Keeble $v$

\footnotetext{
126 N.Y. 397 (1852).

133 Cai. R. 175, 2 Am. Dec. 264 (N.Y. 1805).
} 
Hickeringill $^{14}$ and Young $v$ Hitchens ${ }^{15}$, the three wild animals cases at the heart of Berman and Hafner (1993). The eventual theory that emerges in Bench-Capon and Sartor (2003) is:

Cases: Pierson, Keeble, Young.

Factors: NotCaught, PlaintiffEarningLivelihood, DefendantEarningLivelihood, PlaintiffOwnedLand.

\section{Rules:}

Rule1: NotCaught $\rightarrow$ Defendant.

Rule2: PlaintiffEarningLivelihood $\rightarrow$ Plaintiff.

Rule3: DefendantEarningLivelihood $\rightarrow$ Defendant.

Rule4: NotCaught $\wedge$ DefendantEarningLivelihood $\rightarrow$ Defendant.

Rule Preferences: Rule2 $\succ$ Rule1. Rule4 $\succ$ Rule2. $^{16}$

ValuePreferences: Productivity $\succ$ Clarity. [Productivity,Clarity] $\succ$ Productivity.

Now let us view this an anF. First note that the structure is much simpler than our example in Fig. 1: all the factors are base level factors, and there is just one root node above them (Decision). The rules of Bench-Capon and Sartor (2003) are all just one step and no chaining is used. Thus all the rules must be placed in the acceptance condition of Decision. These acceptance conditions will be:

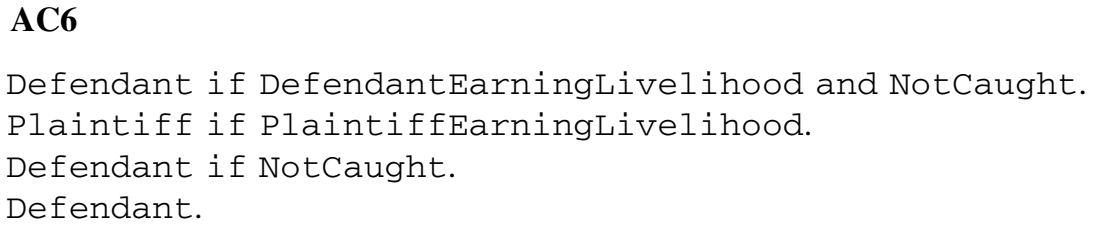

Value preferences are not explicit in the ADF, but we could associate them with rules: Rule1 promotes Clarity, Rules 2 and 3 promote Productivity and Rule 4 promotes both. Thus the ordering in AC6 follows the value preferences of the theory. The result is a much simpler structure, but one which lacks many of the software advantages of a more elaborate ADF as given in Sect. 1.1. In particular the rule base is monolithic, lacking the modularisation typically provided by an ADF. Moreover the flatness of the structure inhibits the transparency of the theory, and the explanation capabilities of an implemented system. The opacity of explanations produced from the theories of Bench-Capon and Sartor (2003) can be seen from Chorley and Bench-Capon (2005).

Turning now to the theory construction operators of Bench-Capon and Sartor (2003), the first is includeCase. This is not needed in the ADF, which has the complete set of cases from the outset. The second, includeFactor, corresponds to

\footnotetext{
14103 ER 1127 (1707).

156 QB 606, 115 ER 228 (1844).

16 There is no precedent to tell us the priority of Rule 3.
} 
adding a node to the ADF. Whether it broadens or narrows the concept to which it is added depends on the party favoured by the factor, and the role played by the new factor in the acceptance condition. Note too that the factor brings with it a value, and we saw that adding a node was often motivated by the desire to introduce a new value into consideration. The third is factorMerging which brings together two factors to act as a conjunctive antecedent. This is similar to narrowing a concept in an $\mathrm{ADF}$ by, e.g. moving from $\mathrm{AC} 2$ to $\mathrm{AC} 1$. The fourth constructor is ruleBroadening, which corresponds to broadening in the ADF, as when we move from AC1 to AC2. The fifth operator is PreferenceFromCase, which corresponds to a change in rule order in an acceptance condition, as discussed in relation to priorities in Sect. 3.3. above. The sixth operator is RulePreferenceFromValuePreference. This also is effected in the ADF by a change in the order of the test in an acceptance condition, but the motivation differs. The same is true of the remaining operators, ArbitraryRulePreference and ArbitraryValuePreference, except these are not motivated by a case. Thus there are clear correspondences between the operators of Bench-Capon and Sartor (2003) and the ways in which an ADF is modified. One difference is that Bench-Capon and Sartor (2003) is much more explicit about the sources of change, and the values. This suggests that we should consider annotating the tests of an ADF with the cases they derive from and the values they promote. In this way we would combine some of the strengths of the theory construction approach with the software engineering advantages of using an ADF. Moreover such annotations would represent the sort of documentation which should accompany any software design.

\section{Concluding remarks}

In this paper we have drawn inspiration from Berman and Hafner (1995) which considers the temporal context of a system based on legal cases. That paper itself develops ideas relating to purpose put forward in Berman and Hafner (1993). This is only natural: while technological developments can make changes in the law necessary, as when the invention of cinema necessitated a rethinking of copyright law, and as perhaps robots and autonomous agents will necessitate changes in the near future, the main driver for legal change remains the social context in which the law operates. The law has a purpose, but this is closely related to the currently favoured social values. Sometimes social change can be seen as undisputed progress, as with the rights of women in the last century, and attitudes to same sex marriage in this century, from which (it is to be hoped) there is no going back. In other changes in social attitude, such as the degree of judicial discretion acceptable, the pendulum swings first one way then another, in accordance with intellectual fashion.

Whatever the source of change, it must be accommodated in the representation of case law domains, and here we have discussed how change can be accommodated in a current proposal for an engineering methodology for such a system, and related this account to previous work on change. 
Perhaps the most interesting feature of Berman and Hafner (1995) is its stress on dimensions. Although dimensions were a feature of legal case based reasoning in HYPO, more than thirty years ago, they have remained largely dormant while reasoning with factors has been fully explored. But in recent years dimensions have been revived as an essential bridge between factors and the facts describing a case from the perspective of the real world, as in Prakken et al. (2015) and Bench-Capon and Bex (2015). It is this kind of prescience that makes the work of Carole and Don on case based reasoning in law still relevant after more than twenty years.

Acknowledgements Since this paper is to appear in a special issue celebrating the life and work of Carole Hafner, we feel that we should acknowledge Carole's contribution to AI and Law research in general and to our research in particular. The debt of the second and third authors to the work of Carole and Don Berman, in particular Berman and Hafner (1993), is considerable: much of our work has explored value-based reasoning in case law, explicitly building upon the teleological aspects of reasoning with cases identified there. Carole and Don were an all too rare example of an equal partnership of AI and Law, with Carole supplying the AI and Don the law. The balance between the disciplines is meticulous: there is a real legal problem and a well thought through practical, computable, solution to that problem. This contrasts with much AI and Law work: all too often we find either a real legal problem and some hand-waving suggestions of how it might be solved, or a computer solution in search of a problem, and the example is at best a toy problem and at worst purely symbolic. Carole and Don showed us what can be done when the two disciplines work together in harmony. If she had done nothing else - and she did a lot of other valuable work, especially relating to conceptual retrieval and ontologies, not to mention her important role in creating an AI and Law community-Carole's contribution to AI and Law in the early nineties papers with Don would represent one of the more significant achievements in the field. After more than twenty years of study, these papers continue to yield fresh insights.

Open Access This article is distributed under the terms of the Creative Commons Attribution 4.0 International License (http://creativecommons.org/licenses/by/4.0/), which permits unrestricted use, distribution, and reproduction in any medium, provided you give appropriate credit to the original author(s) and the source, provide a link to the Creative Commons license, and indicate if changes were made.

\section{References}

Al-Abdulkarim L, Atkinson K, Bench-Capon T (2015) Factors, issues and values: revisiting reasoning with cases. In: Proceedings of the 15th international conference on artificial intelligence and law. ACM, pp 3-12

Al-Abdulkarim L, Atkinson K, Bench-Capon T (2016a) A methodology for designing systems to reason with legal cases using abstract dialectical frameworks. Artif Intell Law 24(1):1-49

Al-Abdulkarim L, Atkinson K, Bench-Capon T (2016b) Angelic secrets: bridging from factors to facts in US trade secrets. In: Proceedings of Jurix 2016 (in press)

Al-Abdulkarim L, Atkinson K, Bench-Capon T (2016c) Statement types in legal reasoning. In: Proceedings of Jurix 2016 (in press)

Aleven V (1997) Teaching case-based argumentation through a model and examples. Ph.D. thesis, University of Pittsburgh

Araszkiewicz M, Łopatkiewicz A, Zienkiewicz A, Zurek T (2015) Representation of an actual divorce dispute in the parenting plan support system. In: Proceedings of the 15 th international conference on artificial intelligence and law. ACM, pp 166-170

Ashley KD (1991) Modeling legal arguments: reasoning with cases and hypotheticals. MIT Press, Cambridge

Ashley KD, Brüninghaus S (2003) A predictive role for intermediate legal concepts. In: Proceedings of JURIX, pp 153-162 
Ashley KD, Lynch C, Pinkwart N, Aleven V (2008) A process model of legal argument with hypotheticals. In: JURIX, vol 189, pp 1-10

Atkinson K, Bench-Capon T (2005) Legal case-based reasoning as practical reasoning. Artif Intell Law 13(1):93-131

Bench-Capon T (2009) Towards computational modelling of supreme court opinions: Furman v Georgia. In: Atkinson K (ed) Modelling legal cases. IDT Series, Universitat Autònoma de Barcelona Barcelona, pp 329-42

Bench-Capon TJM (2002) The missing link revisited: the role of teleology in representing legal argument. Artif Intell Law 10(1-3):79-94

Bench-Capon T (2012) Representing Popov v Hayashi with dimensions and factors. Artif Intell Law 20(1):15-35

Bench-Capon T, Coenen F (1991) Exploiting isomorphism: development of a KBS to support British coal insurance claims. In: Proceedings of the 3rd international conference on artificial intelligence and law. ACM, pp 62-68

Bench-Capon T, Rissland EL (2001) Back to the future: dimensions revisited. In: Proceedings of JURIX 2001, pp 41-52

Bench-Capon T, Sartor G (2003) A model of legal reasoning with cases incorporating theories and values. Artif Intell 150(1):97-143

Bench-Capon T, Gordon TF (2009) Isomorphism and argumentation. In: Proceedings of the 12th international conference on artificial intelligence and law. ACM, pp 11-20

Bench-Capon T, Bex F (2015) Cases and stories, dimensions and scripts. In: Legal knowledge and information systems: JURIX 2015: the twenty-eighth annual conference, vol 279. IOS Press, p 11

Bench-Capon T, Prakken H, Wyner A, Atkinson K (2013) Argument schemes for reasoning with legal cases using values. In: Proceedings of the fourteenth international conference on artificial intelligence and law. ACM, pp 13-22

Berman DH, Hafner CD (1991) Incorporating procedural context into a model of case-based legal reasoning. In: Proceedings of the 3rd international conference on artificial intelligence and law. ACM, pp 12-20

Berman DH, Hafner CD (1993) Representing teleological structure in case-based legal reasoning: the missing link. In: Proceedings of the 4th international conference on artificial intelligence and law. ACM, pp 50-59

Berman DH, Hafner CD (1995) Understanding precedents in a temporal context of evolving legal doctrine. In: Proceedings of the 5th international conference on artificial intelligence and law. ACM, pp 42-51

Branting LK (1991) Reasoning with portions of precedents. In: Proceedings of the 3rd international conference on artificial intelligence and law. ACM, pp 145-154

Bratley P, Frémont J, Mackaay E, Poulin D (1991) Coping with change. In: Proceedings of the 3rd international conference on artificial intelligence and law. ACM, pp 69-76

Brewka G, Woltran S (2010) Abstract dialectical frameworks. In: Proceedings of KR-2010, pp 101-111

Brewka G, Ellmauthaler S, Strass H, Wallner JP, Woltran S (2013) Abstract dialectical frameworks revisited. In: Proceedings of the twenty-third international joint conference on artificial intelligence. AAAI Press, pp 803-809

Bruninghaus S, Ashley KD (2003) Predicting outcomes of case based legal arguments. In Proceedings of the 9th international conference on artificial intelligence and law. ACM, pp 233-242

Chorley A, Bench-Capon T (2005) Agatha: using heuristic search to automate the construction of case law theories. Artif Intell Law 13(1):9-51

Christie G (2012) The notion of an ideal audience in legal argument. Springer, Berlin

Coenen F, Bench-Capon T (1993) Maintenance of knowledge-based systems: theory, techniques and tools. Academic Press, London

Connolly T M, Begg C E (2004) Database solutions: a step-by-step guide to building databases. Pearson Education, Upper Saddle River

Dung PM (1995) On the acceptability of arguments and its fundamental role in nonmonotonic reasoning, logic programming and n-person games. Artif Intell 77(2):321-357

Hafner CD (1987) Conceptual organization of case law knowledge bases. In: Proceedings of the 1st international conference on artificial intelligence and law. ACM, pp 35-42

Hafner CD, Berman DH (2002) The role of context in case-based legal reasoning: teleological, temporal, and procedural. Artif Intell Law 10(1-3):19-64 
Hafner CD, Lauritsen M (2007) Extending the power of automated legal drafting technology. In: JURIX, vol 165, pp 59-68

Henderson J, Bench-Capon T (2001) Dynamic arguments in a case law domain. In: Proceedings of the 8th international conference on Artificial intelligence and law. ACM, pp 60-69

Horty JF, Bench-Capon TJM (2012) A factor-based definition of precedential constraint. Artif Intell Law 20(2):181-214

Levi EH (1961) An introduction to legal reasoning. University of Chicago Press, Chicago

Lindahl L, Odelstad J (2006) Intermediate concepts in normative systems. In: Deontic logic and artificial normative systems. Springer, pp 187-200

Noy NF, Hafner CD (1997) The state of the art in ontology design: a survey and comparative review. AI Mag 18(3):53-74

Prakken H (2002) An exercise in formalising teleological case-based reasoning. Artif Intell Law 10(1-3):113-133

Prakken H, Wyner A, Bench-Capon T, Atkinson K (2015) A formalization of argumentation schemes for legal case-based reasoning in ASPIC+. J Logic Comput 25(5):1141-1166

Priddle-Higson A (2010) Computational models of ontology evolution in legal reasoning. M.Phil. Thesis, The University of Edinburgh

Rissland EL (1989) Dimension-based analysis of hypotheticals from supreme court oral argument. In: Proceedings of the 2nd international conference on artificial intelligence and law. ACM, pp 111-120

Rissland EL, Friedman MT (1995) Detecting change in legal concepts. In: Proceedings of the 5th international conference on artificial intelligence and law. ACM, pp 127-136

Rissland EL, Xu X (2011) Catching gray cygnets: an initial exploration. In Proceedings of the 13th international conference on artificial intelligence and law. ACM, pp 151-160

Sartor G (2002) Teleological arguments and theory-based dialectics. Artif Intell Law 10(1-3):95-112

Sergot MJ, Sadri F, Kowalski RA, Kriwaczek F, Hammond P, Cory HT (1986) The British Nationality Act as a logic program. Commun ACM 29(5):370-386

Skalak DB, Rissland EL (1992) Arguments and cases: an inevitable intertwining. Artif Intell Law $1(1): 3-44$

Wyner A, Bench-Capon T (2009) Modelling judicial context in argumentation frameworks. J Logic Comput 19(6):941-968

Wyner A, Bench-Capon T, Atkinson K (2007) Arguments, values and baseballs: Representation of Popov v. Hayashi. In: Proceedings of JURIX 2007, pp 151-160

Wyner A, Hoekstra R (2012) A legal case owl ontology with an instantiation of Popov v Hayashi. Artif Intell Law 20(1):83-107 